\title{
Re-irradiation stereotactic body radiotherapy for spinal metastases: a multi-institutional outcome analysis
}

\author{
Ahmed Hashmi, MD, ${ }^{1}$ Matthias Guckenberger, MD, ${ }^{2,3}$ Ron Kersh, MD, ${ }^{4}$ Peter C. Gerszten, MD, ${ }^{5}$ \\ Frederick Mantel, MD, ${ }^{2}$ Inga S. Grills, MD, ${ }^{6}$ John C. Flickinger, MD, ${ }^{7}$ John H. Shin, MD, ${ }^{8}$ \\ Daniel K. Fahim, MD, ${ }^{9}$ Brian Winey, PhD, ${ }^{10}$ Kevin Oh, MD, ${ }^{10}$ B. C. John Cho, MD, PhD, ${ }^{11}$ \\ Daniel Létourneau, PhD, ${ }^{11}$ Jason Sheehan, MD, PhD, ${ }^{12}$ and Arjun Sahgal, MD1
}

\begin{abstract}
1Department of Radiation Oncology, Sunnybrook Odette Cancer Centre, and ${ }^{11}$ Department of Radiation Oncology, Princess Margaret Cancer Center, University of Toronto, Ontario, Canada; ${ }^{\circ}$ Department of Radiation Oncology, Riverside Medical Center, Newport News, Virginia; Departments of ${ }^{5}$ Neurosurgery and ${ }^{7}$ Radiation Oncology, University of Pittsburgh Medical Center, Pittsburgh, Pennsylvania; ${ }^{2}$ Department of Radiation Oncology, University of Wuerzburg, Germany; Departments of ${ }^{6}$ Radiation Oncology and ${ }^{9}$ Neurosurgery, William Beaumont Hospital, Royal Oak, Michigan; Departments of ${ }^{8}$ Neurosurgery and ${ }^{10}$ Radiation Oncology, Massachusetts General Hospital, Boston, Massachusetts; ${ }^{12}$ Department of Neurosurgery, University of Virginia Health System, Charlottesville, Virginia; and ${ }^{3}$ Department of Radiation Oncology, University of Zurich, Zurich, Switzerland
\end{abstract}

OBJECTIVE This study is a multi-institutional pooled analysis specific to imaging-based local control of spinal metastases in patients previously treated with conventional external beam radiation therapy (cEBRT) and then treated with reirradiation stereotactic body radiotherapy (SBRT) to the spine as salvage therapy, the largest such study to date.

METHODS The authors reviewed cases involving 215 patients with 247 spinal target volumes treated at 7 institutions. Overall survival was calculated on a patient basis, while local control was calculated based on the spinal target volume treated, both using the Kaplan-Meier method. Local control was defined as imaging-based progression within the SBRT target volume. Equivalent dose in 2-Gy fractions (EQD2) was calculated for the cEBRT and SBRT course using an $\alpha / \beta$ of 10 for tumor and 2 for both spinal cord and cauda equina.

RESULTS The median total dose/number of fractions of the initial cEBRT was $30 \mathrm{~Gy} / 10$. The median SBRT total dose and number of fractions were $18 \mathrm{~Gy}$ and 1, respectively. Sixty percent of spinal target volumes were treated with singlefraction SBRT (median, 16.6 Gy and EQD2/10 = 36.8 Gy), and 40\% with multiple-fraction SBRT (median 24 Gy in 3 fractions, $E Q D 2 / 10=36 \mathrm{~Gy}$ ). The median time interval from cEBRT to re-irradiation SBRT was 13.5 months, and the median duration of patient follow-up was 8.1 months. Kaplan-Meier estimates of 6 - and 12-month overall survival rates were $64 \%$ and $48 \%$, respectively; $13 \%$ of patients suffered a local failure, and the 6 - and 12 -month local control rates were $93 \%$ and $83 \%$, respectively. Multivariate analysis identified Karnofsky Performance Status (KPS) $<70$ as a significant prognostic factor for worse overall survival, and single-fraction SBRT as a significant predictive factor for better local control. There were no cases of radiation myelopathy, and the vertebral compression fracture rate was $4.5 \%$.

CONCLUSIONS Re-irradiation spine SBRT is effective in yielding imaging-based local control with a clinically acceptable safety profile. A randomized trial would be required to determine the optimal fractionation.

http://thejns.org/doi/abs/10.3171/2016.4.SPINE151523

KEY WORDS spinal metastases; re-irradiation; stereotactic body radiotherapy; stereotactic radiosurgery; salvage; oncology

$\mathrm{S}$ PINAL metastases will develop in $40 \%$ of patients diagnosed with cancer. Most of these patients will be offered short-course palliative conventional external beam radiation therapy (cEBRT), which has been associated with short-term pain control and low rates of complete response to pain. ${ }^{24}$ Furthermore, approximately
$10 \%-20 \%$ of patients will suffer pain progression following cEBRT, requiring retreatment. ${ }^{18}$ Therefore, the burden of patients needing re-irradiation to spinal metastases is significant, considering the prevalence of the disease.

Retreatment options are limited and have typically consisted of a second course of cEBRT delivering a lower

ABBREVIATIONS cEBRT = conventional EBRT; CNT = critical neural tissue; $\mathrm{D}_{\max }=$ point maximum dose; EBRT = external beam radiation therapy; $\mathrm{EQD2}=$ equivalent dose in 2-Gy fractions; ESSC = Elekta Spine Study Consortium; KPS = Karnofsky Performance Status; SBRT = stereotactic body radiotherapy; VCF = vertebral compression fracture.

SUBMITTED December 22, 2015. ACCEPTED April 6, 2016.

INCLUDE WHEN CITING Published online June 24, 2016; DOI: 10.3171/2016.4.SPINE151523. 
dose than the first course or a biologically equivalent dose in order to respect cumulative risks of radiation-induced toxicities. ${ }^{8}$ This strategy has been investigated in a landmark randomized trial evaluating re-irradiation cEBRT doses of 20 Gy in 5 fractions and 8 Gy in 1 fraction for painful bone metastases requiring retreatment. ${ }^{8}$ The trial confirmed that response rates are suboptimal, with only $30 \%$ of patients achieving an overall pain response to treatment. These data highlight the need for more effective treatments in the retreatment indication. It is also important to recognize that the decision to re-irradiate with additional cEBRT limits further treatment options significantly due to toxicity concerns, and this is of particular relevance to spinal metastases because the spinal cord and cauda equina (critical neural tissue [CNT]) can tolerate only so much cumulative exposure.

Stereotactic body radiotherapy (SBRT) has been defined by several national and international bodies and associations as the precise delivery of highly conformal image-guided hypofractionated (> 5 Gy/fraction) EBRT, delivered in a single fraction or a few fractions, to an extracranial body target with doses at least biologically equivalent to those considered radical when given over a protracted course. ${ }^{27}$ Spine SBRT is an emerging treatment option and is designed to escalate the dose to the spinal metastasis while maintaining a lower dose exposure for critical neural tissues (CNTs, namely the spinal cord and the thecal sac as a surrogate for the cauda equina). In the retreatment indication, spine SBRT has major potential for effective palliation and local tumor control, because substantially higher radiation doses are delivered as compared with the first course of cEBRT. ${ }^{23}$ The few retreatment SBRT series that have been reported indicate high rates of treatment efficacy, but these series are limited with respect to sample size and are single-center studies by design. ${ }^{23}$ The present study consists of the largest multi-institutional pooled analysis reporting on imagingbased local control rates in patients previously treated with cEBRT and subsequently treated with re-irradiation SBRT with salvage intent.

\section{Methods}

\section{Patient Population and SBRT Technique}

Seven international centers from the United States, Canada, and Germany, took part in this research ethics board-approved retrospective study. A total of 215 patients were included. Each patient had spinal metastases treated with SBRT with salvage intent (failure of prior cEBRT). All centers were members of the Elekta Spine Study Consortium (ESSC). ${ }^{14,15}$ The principles and practice of each member of this consortium's technique, approach to organs at risk, targeting, and dosimetric aims have been previously reported..$^{15}$

Patients were treated most frequently with an Elekta (Elekta AB) subcentimeter multileaf collimator $(4 \mathrm{~mm})$ linear accelerator-based SBRT apparatus equipped with cone-beam CT (CBCT)-based image-guidance, online correction of setup errors in 6 degrees of freedom using the robotic HexaPOD patient positioning platform (Elekta $\mathrm{AB}$ ), and either intensity-modulated radiotherapy or volumetric modulated radiotherapy. Patients were immobilized using the BodyFIX system (Elekta $\mathrm{AB}$ ) for tumors below T-4, and for tumors at T-4 and above (cranially) in a head and neck 5-point thermoplastic mask. This technology has been reported to yield, based on a strict repositioning threshold of $1 \mathrm{~mm}$ and $1^{\circ}$, target localization within $1.2 \mathrm{~mm}$ and $0.9^{\circ}$ with $95 \%$ confidence..$^{19}$ Treatment planning systems and technique were not standardized between the different institutes. Contouring of the target volume was typically based on the International Spine Radiosurgical Consortium (ISRC) guidelines. ${ }^{9}$ Technical and delivery details can be reviewed in prior reported studies that include a survey of ESSC institutional practices and delivery techniques. ${ }^{14,15}$

Biologically equivalent dose (BED) in 2-Gy-equivalent fractions, known as the equivalent dose in 2-Gy fractions (EQD2), was calculated for the tumor based on the prescription dose and number of fractions and the CNT based on the point maximum dose $\left(\mathrm{D}_{\max }\right)$ to adjust for variation in dose-fractionation schemes among institutions. An $\alpha / \beta$ ratio of 10 was used for tumor calculation and an $\alpha / \beta$ ratio of 2 for the CNT. The spinal cord was typically contoured according to the spinal cord plus a $1.5-2.0 \mathrm{~mm}$ PRV, and the cauda equina contoured according to the thecal sac.

\section{Radiographic and Clinical Assessments After SBRT}

Local control was assessed radiologically with MRI, and in some centers confirmed with FDG-PET. Local failure was defined as tumor progression in the previously treated volume as determined by the radiation oncologist and radiologist in accordance with the recently reported Spine Response Assessment In Neuro-Oncology (SPINO) guideline. ${ }^{29}$ Pain status at baseline and follow-up was categorized as none, mild to moderate, or severe. No specific criteria were applied. We evaluated the SBRT spinal segment and characterized the target volume as single for isolated metastases and multiple if the target consisted of contiguous vertebrae. In situations where noncontiguous single spinal segments were treated, then each segment was considered as a single target rather than considering the lesions as a multiple-segment target volume.

\section{Statistical Methods}

Statistical analysis was performed on Statistica X (Statsoft), and all statistical tests were 2-sided. The Pearson chi-square or Fisher exact test and Kruskal-Wallis ANOVA were used to compare categorical and continuous variable between groups. Receiver operating characteristics curves were used to test prognostic factors in predicting outcome with their performances measured based on the area under the curve. The Kaplan-Meier method was used to estimate the likelihood of events from the date of SBRT to last follow-up. Log-rank test was used to compare differences in the univariate analysis. A Cox proportional hazard model was used to perform multivariate analysis.

\section{Results}

\section{Patient and Tumor Characteristics}

Table 1 summarizes selected baseline patient and treatment-related characteristics. A total of 215 patients and 
TABLE 1. Summary of patient and tumor characteristics for the total cohort (247 tumors and 215 patients)*

\begin{tabular}{|c|c|}
\hline Characteristic & Value \\
\hline \multicolumn{2}{|l|}{ Sex } \\
\hline M & $48.6 \%$ \\
\hline $\mathrm{F}$ & $51.4 \%$ \\
\hline \multicolumn{2}{|l|}{ Age in yrs } \\
\hline Median & 62 \\
\hline Range & $18-89$ \\
\hline \multicolumn{2}{|l|}{ Primary histology } \\
\hline Breast & $29.1 \%$ \\
\hline Non-small cell lung cancer & $16.6 \%$ \\
\hline Kidney & $13.1 \%$ \\
\hline Prostate & $7.3 \%$ \\
\hline Colon & $5.7 \%$ \\
\hline Melanoma & $3.2 \%$ \\
\hline Other & $25 \%$ \\
\hline \multicolumn{2}{|l|}{ Multiple/solitary mets } \\
\hline Multiple & $89 \%$ \\
\hline Solitary & $11 \%$ \\
\hline \multicolumn{2}{|l|}{ Location w/in the spine } \\
\hline Cervical & $14.6 \%$ \\
\hline Thoracic & $49.0 \%$ \\
\hline Lumbar & $27.1 \%$ \\
\hline Sacral & $9.3 \%$ \\
\hline \multicolumn{2}{|l|}{ Baseline pain } \\
\hline None & $9.7 \%$ \\
\hline Mild to moderate & $78.1 \%$ \\
\hline Severe & $12.1 \%$ \\
\hline \multicolumn{2}{|l|}{ Bilsky epidural grade $\dagger$} \\
\hline 0 & $25.1 \%$ \\
\hline $1 a-c$ & $60.1 \%$ \\
\hline 2 & $9 \%$ \\
\hline 3 & $5.8 \%$ \\
\hline \multicolumn{2}{|l|}{ Baseline VCF† } \\
\hline No & $166(67.2 \%)$ \\
\hline Yes & $81(32.8 \%)$ \\
\hline \multicolumn{2}{|l|}{ Prior surgery† } \\
\hline Surgical decompression & $28.2 \%$ \\
\hline Percutaneous cement augmentation & $7.2 \%$ \\
\hline Instrumentation \& stabilization & $10.6 \%$ \\
\hline $\begin{array}{l}\text { Median time in mos from primary tumor Dx to } \\
\text { re-irradiation SBRT (range) } \dagger\end{array}$ & $47.5(9.5-397.6)$ \\
\hline $\begin{array}{l}\text { Median time in mos from cEBRT to re-irradiation } \\
\text { SBRT (range) } \dagger\end{array}$ & $13.5(0.2-107.3)$ \\
\hline Median no. of SBRT Fx (range)† & $1.0(1.0-20.0)$ \\
\hline Median SBRT tumor EQD2/10 in Gy (range)† & $36.0(12.0-66.7)$ \\
\hline Median SBRT CNT EQD2/2 D max in Gy (range)† & $24.6(0-70.1)$ \\
\hline Median cumulative tumor EQD2/10 in Gy (range) $\dagger$ & $68.2(33.7-116.0)$ \\
\hline $\begin{array}{l}\text { Median cumulative CNT EQD2/2 } D_{\max } \text { in Gy } \\
\text { (range) } \dagger\end{array}$ & $60.8(14.0-107.6)$ \\
\hline
\end{tabular}

CONTINUED IN NEXT COLUMN
CONTINUED FROM PREVIOUS COLUMN

TABLE 1. Summary of patient and tumor characteristics for the total cohort (247 tumors and 215 patients)*

\begin{tabular}{|c|c|}
\hline Characteristic & Value \\
\hline \multicolumn{2}{|l|}{ Single-Fx SBRT† } \\
\hline$\%$ of target volumes & $59.9 \%$ \\
\hline Median total dose in Gy (range)† & $16.6(8-21.2)$ \\
\hline \multicolumn{2}{|l|}{$\%$ dosed to } \\
\hline 8-15.9 Gy & $34 \%$ \\
\hline 16-18 Gy & $40 \%$ \\
\hline 18-22 Gy & $26 \%$ \\
\hline \multicolumn{2}{|l|}{ Multiple-Fx SBRT† } \\
\hline$\%$ of target volumes & $40.1 \%$ \\
\hline Median total dose in Gy (range) & $24(14-50)$ \\
\hline Median no. of Fx (range) $\dagger$ & $3(2-20)$ \\
\hline \multicolumn{2}{|l|}{$\%$ treated $w /$ dose per Fx of } \\
\hline 2-5 Gy & $12 \%$ \\
\hline 6-6.9 Gy & $23 \%$ \\
\hline 7-7.9 Gy & $20 \%$ \\
\hline 8-8.9 Gy & $39 \%$ \\
\hline 9-20 Gy & $4 \%$ \\
\hline Median clinical follow-up in mos (range) & $8.1(0.1-52.6)$ \\
\hline Median imaging follow-up in mos (range) & $7.7(0.0-51.1)$ \\
\hline \multicolumn{2}{|c|}{ 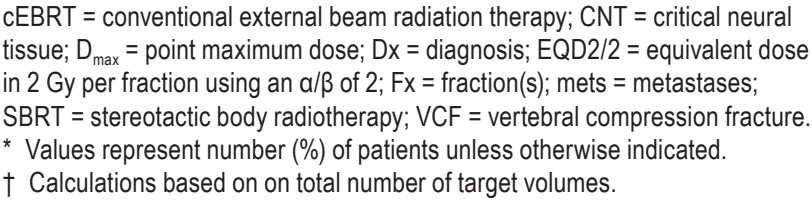 } \\
\hline
\end{tabular}

247 spinal target volumes were followed with a median clinical follow-up time of 8.1 months, and the median imaging-based follow-up time was 7.7 months. SBRT was performed as salvage treatment after cEBRT failures, and no boost practice was included in this series. Eighty-nine percent of patients had multiple contiguous vertebrae as the target volume (median 2 segments); $85.2 \%$ had radiographic evidence of no epidural disease or low-grade epidural disease (indenting the thecal sac but not deforming the spinal cord), based on the Bilsky classification ${ }^{2}$ (no more than a Grade 1c status). Only $14.8 \%$ had features of high-grade epidural disease (Bilsky Grade 2 or 3 status). Paraspinal disease was present in 55.8\% of patients, and $32.8 \%$ had preexisting vertebral compression fractures. Baseline mild to moderate pain prior to SBRT was reported in $78.1 \%$ of the patients. Forty-six percent had undergone surgical treatment prior to SBRT; the surgical procedures are summarized in Table 1 .

\section{SBRT Parameters}

The median SBRT total dose was 18 Gy (range 8-50 Gy), the median number of fractions was 1 (range 1-20), the median EQD2/10 was 36 Gy (range 12.0-66.7 Gy), and the median CNT D ${ }_{\max }$ EQD2/2 was 24.6 (range 0-70.1 Gy). The median cEBRT total dose and number of fractions were $30 \mathrm{~Gy}$ and 10 . Including prior cEBRT, the me- 


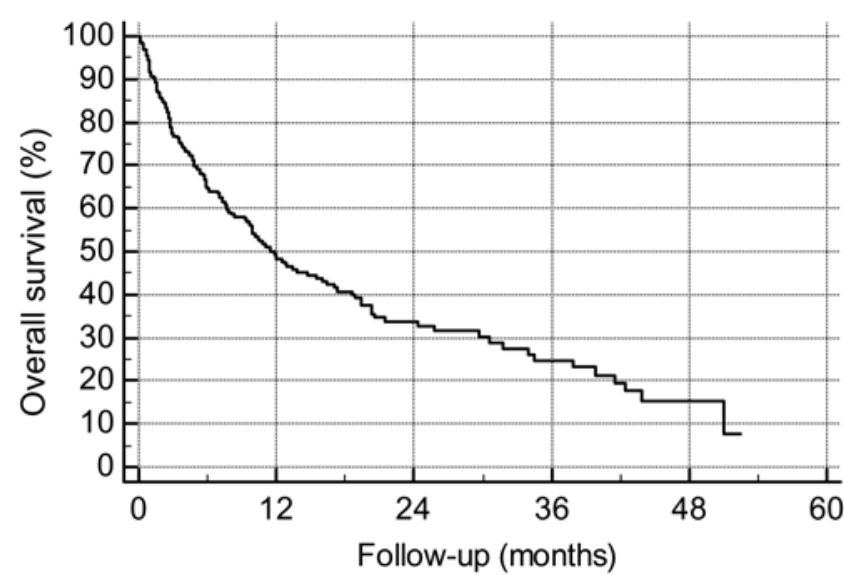

Number at risk 215 82

17

4

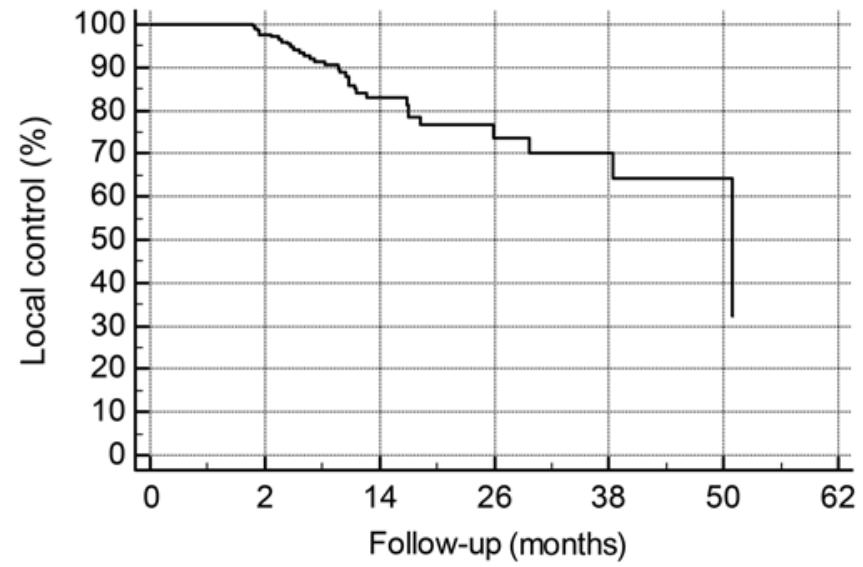

FIG. 1. Kaplan-Meier curves showing the overall survival after SBRT in the cohort of 215 patients (left) and local control for the 235 treated target volumes (right).

dian cumulative EQD2/10 for tumor was $68.2 \mathrm{~Gy}$, and the cumulative CNT EQD2/2 $\mathrm{D}_{\text {max }}$ was $60.8 \mathrm{~Gy}$.

When segregating those patients treated with multiplefraction SBRT (40\%) versus single-fraction SBRT (60\%), the EQD2/10 for tumor was 36.0 Gy and $36.8 \mathrm{~Gy}$, respectively, and the EQD2/2 to CNT was 15.3 Gy and $30 \mathrm{~Gy}$, respectively. The cumulative EQD2/10 for tumor was 66.9 Gy and $67.6 \mathrm{~Gy}$, respectively, and the EQD2/2 to CNT was 47.8 Gy and $65.6 \mathrm{~Gy}$, respectively. The overall median interval between previous cEBRT and re-irradiation SBRT was 13.5 months. For single-fraction versus multiplefraction SBRT, the time intervals between prior cEBRT and re-irradiation SBRT were 12 months and 16 months, respectively.

\section{Clinical and Radiological Outcomes}

One hundred thirty-three deaths were observed. The median overall survival was 11.8 months (range 8.6-15.0 months) with actuarial rates of $64 \%$ and $48 \%$ at 6 and 12 months, respectively. The Kaplan-Meier plot is shown in Fig. 1, displaying that $13 \%$ of patients suffered a local failure. The actuarial rate was $93 \%$ and $83 \%$ at 6 and 12 months, respectively. The median time to local failure for the entire cohort was 8.3 months (range 0.7-50.9 months). The median time to local failure was 8.2 months (range 2.6-17 months) in the single-fraction SBRT cohort and 11.3 (range 0.7-50.9) months in the multiple-fraction cohort.

Two hundred fourteen of the 215 patients had sufficient documentation of baseline predictive factors for survival analysis, with KPS at baseline a mandatory a priori field. Therefore, we present the survival prognostic factor univariate and multivariate analysis for this cohort. Data from at least 3 months of follow-up and at least 3 follow-up images were available for assessment of local control for 235 of 247 target volumes. Therefore, the predictive factor analysis for local control is based on this cohort. Table 2 summarizes those patient and treatment baseline variables that achieved significance $(\mathrm{p}<0.05)$ on univariate analysis for both local control and overall survival. Multivariate analysis identified a KPS $<70$ to be the only significant prognostic variable for survival $(\mathrm{p}=$ $0.02,95 \% \mathrm{CI}=0.41-0.95$, Fig. 2 ). With respect to local control, single-fraction SBRT was identified as the only significant predictive factor with single-fraction SBRT yielding better local control than multiple-fraction SBRT $(\mathrm{p}=0.002,95 \% \mathrm{CI}=1.7-13.5$, Fig. 2$)$. With respect to pain control, $74.3 \%$ of patients reported clinical improvement in pain. At last follow-up, pain was present in only $46.1 \%$ of patients.

\section{Adverse Effects Following SBRT}

Following SBRT, $11.3 \%$ of patients experienced dysphagia, $3 \%$ had dermatitis, and $12.4 \%$ had increased pain (the pain flare was mild to moderate in $65.3 \%$ of these cases and severe in $34.7 \%$ ). With respect to late effects, no patient developed radiation-induced myelopathy or radiculopathy. Eleven vertebral compression fractures (VCFs) were observed (rate of 4.5\%): 5 were de novo and 6 were fracture progression (rates of $2.1 \%$ and $2.5 \%$, respectively).

\section{Discussion}

This study reports a comprehensive multi-institutional analysis of a large cohort of patients treated with re-irradiation SBRT for metastatic disease in the spine. The study found a favorable 12-month local control rate of $83 \%$ and a 12 -month overall survival rate of $48 \%$. The patient population consisted predominantly of lung, breast, and kidney cancer patients with metastatic lesions in thoracic and/or lumbar spinal segments and no or low-grade epidural disease.

With respect to local control, the data from the study by Garg et al. ${ }^{12}$ (as one of the only prospective retreatment SBRT series reported) consisted of outcomes for 59 patients and 63 tumors. The retreatment SBRT doses were $30 \mathrm{~Gy}$ in 5 fractions or $27 \mathrm{~Gy}$ in 3 fractions, and the CNT dose limits were less than 9-10 Gy. The authors reported a local control rate of $76 \%$ at 1 year, which is similar to our reported rate of $83 \%$. Table 3 is a summary of the pub- 
TABLE 2. Univariate analysis identifying those factors with a $\mathrm{p}<$ 0.1 for overall survival and local control

\begin{tabular}{lr}
\hline \multicolumn{1}{c}{ Factor } & p Value \\
\hline \multicolumn{2}{l}{ Overall survival factors } \\
\hline Sex (M/F) & 0.036 \\
\hline Performance status: KPS $\geq 70$ & $<0.001$ \\
\hline Solitary mets & 0.017 \\
\hline Presence of visceral mets & $<0.001$ \\
\hline Controlled systemic disease & 0.005 \\
\hline Time from primary Dx to re-irradiation SBRT & 0.090 \\
\hline Time from cEBRT to re-irradiation SBRT & 0.004 \\
\hline FDG-PET imaging for target delineation & 0.064 \\
\hline Local control factors & 0.021 \\
\hline Sex (M/F) & 0.001 \\
\hline Presence of visceral mets & 0.013 \\
\hline Initial curative treatment of primary disease & 0.011 \\
\hline Prior bisphosphonate treatment (yes/no) & 0.063 \\
\hline Time interval from primary diagnosis to re-irradiation & \\
\hline SBRT & $<0.001$ \\
\hline No. of Fx (single vs multiple) & 0.009 \\
\hline Primary site & 0.082 \\
\hline Location: cervical, thoracic, lumbar, or sacral spine & 0.078 \\
\hline Osteolytic/sclerotic & \\
\hline
\end{tabular}

lished literature specific to retreatment SBRT, and we observe that our rates of survival and local control are consistent with those reported by other authors. To date there are no randomized trials comparing re-irradiation cEBRT to SBRT to definitively confirm superior efficacy.

With respect to overall survival, on multivariate analysis, performance status at the time of retreatment SBRT was observed to be the only statistically significant prognostic factor. Figure 2 describes the survival results for those patients with a KPS $<70$ versus $\geq 70$, determined at the time of retreatment SBRT. At 1 year after SBRT, $1.4 \%$ of patients with a KPS $<70$ were alive as opposed to $36.9 \%$ of patients with a KPS $\geq 70$. Our observation of KPS as a prognostic factor is consistent with Damast et al. ${ }^{10}$ in their re-irradiation SBRT series, and from Chao et al., ${ }^{5}$ who also report on the prognostic capacity of KPS but in patients with no prior radiation therapy treated with spine SBRT. Thus far the spine SBRT literature supports the American Society for Radiation Oncology recommendations that a poor KPS (KPS < 40-50) can be considered an exclusion criterion for spine SBRT. ${ }^{21}$ Our data support its application to the retreatment indication. Moreover, patients in this population usually have already undergone a substantial amount of treatment and are relatively far along the trajectory of their metastatic disease, and a KPS $\geq 70$ may be an appropriate inclusion criteria. However, it is important to note that if a patient's KPS is $<70$ due to the spinal metastases to be treated, aggressive treatment of the spinal metastases may lead to improvement of the KPS. Therefore, in determining whether re-irradiation SBRT is appropriate in any given case, it is essential to consider the individual patient and his or her specific needs.

With respect to local control, from the literature review summarized in Table 3, the presence of epidural disease, lack of space between the CNT and target, paraspinal disease extension, dose, and a shorter time interval between cEBRT and SBRT have been predictors. Our multivariate analysis identified retreatment SBRT with a single fraction to be a positive predictive factor, as compared with multiple-fraction SBRT. Figure 2 illustrates the local control rates for single- versus multiple-fraction SBRT. At 1 year, local control in those treated with single-fraction SBRT was $90 \%$, compared with $73 \%$ in those treated with multiple-fraction SBRT.

Why was this fractionation result observed? With respect to the tumor, for single-fraction and multiplefraction SBRT, both the SBRT EQD2/10 and cumulative EQD2/10 were similar (36.0 Gy and 66.9 Gy, and 36.8 Gy and 67.6 Gy, respectively). However, the CNT EQD2/2 $\mathrm{D}_{\max }$ and cumulative CNT EQD2/2 $\mathrm{D}_{\max }$ were greater for single-fraction SBRT than for multiple-fraction SBRT (30 Gy and 65.6 Gy, and 15.3 Gy and 47.8 Gy, respectively). When applied to univariate analysis, these factors failed to reach significance, and this may be a function of the small number of events in a small patient cohort. However, based on the physical CNT EQD2/2 SBRT $D_{\text {max }}$ being approximately $50 \%$ lower in the multiple-fraction cohort, we surmise that this (the CNT EQD22 SBRT $D_{\max }$ ) may still explain the result-the implication being that the epidural space and effectively the posterior aspect of the vertebral body bone were relatively underdosed in this cohort. We
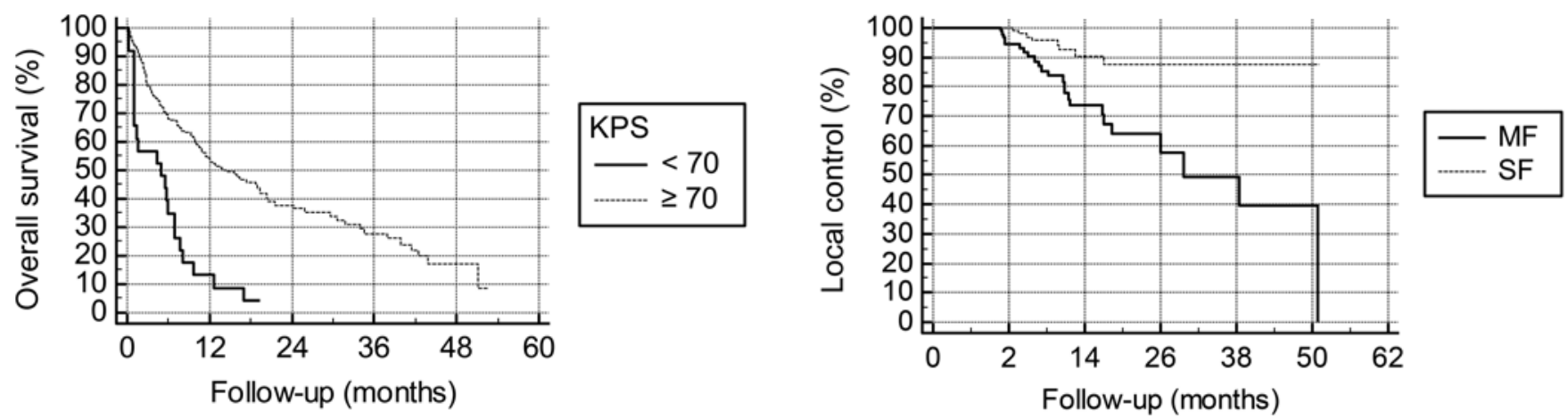

FIG. 2. Kaplan-Meier curves showing overall survival for patients with a KPS $\geq 70$ and KPS $<70(p=0.028)$ and local control for target volumes treated with single-fraction (SF) and multiple-fraction (MF) SBRT ( $p=0.002$ ). 
TABLE 3. Summary of the current literature specific to re-irradiation SBRT

\begin{tabular}{|c|c|c|c|c|c|c|c|c|}
\hline $\begin{array}{c}\text { Authors \& } \\
\text { Year }\end{array}$ & $\begin{array}{l}\text { No. of } \\
\text { Tumors/Pts } \\
\text { Treated }\end{array}$ & $\begin{array}{l}\text { Median } \\
\text { Follow- } \\
\text { Up (mos) }\end{array}$ & $\begin{array}{l}\text { Local } \\
\text { Control }\end{array}$ & $\begin{array}{l}\text { Complete } \\
\text { Pain } \\
\text { Response }\end{array}$ & OS & $\begin{array}{c}\text { Median Tumor Dose/ } \\
\text { No. of Fractions } \\
\text { (previous cEBRT) }\end{array}$ & $\begin{array}{c}\text { Significant } \\
\text { Predictors of Local } \\
\text { Control }\end{array}$ & $\begin{array}{c}\text { Significant } \\
\text { Prognostic } \\
\text { Factors for OS }\end{array}$ \\
\hline $\begin{array}{l}\text { Sahgal et al., } \\
2009\end{array}$ & $37 / 25$ & 7 & $96 \% @ 1 \mathrm{yr}$ & NA & $\begin{array}{c}45 \% @ 2 \\
y r s\end{array}$ & $\begin{array}{l}24 \text { Gy/3 Fx (median } \\
\text { dose } 36 \text { Gy/14 Fx) }\end{array}$ & $\begin{array}{c}\text { Distance btwn GTV } \\
\quad \& \text { CNS }<1 \mathrm{~mm}\end{array}$ & NA \\
\hline $\begin{array}{l}\text { Choi et al., } \\
2010\end{array}$ & $51 / 42$ & 7 & $\begin{array}{l}87 \% @ 6 \\
\text { mos/73\% } \\
\text { @ } 1 \mathrm{yr}\end{array}$ & $65 \%$ & $\begin{array}{c}68 \% @ \\
1 \mathrm{yr}\end{array}$ & $\begin{array}{r}\text { Median } 20 \mathrm{~Gy} / 2 \mathrm{Fx} \\
\text { (median cEBRT } \\
\text { EQD2 = } 40 \mathrm{~Gy} \text { ) }\end{array}$ & $\begin{array}{l}<12 \text {-mo time inter- } \\
\text { val btwn cEBRT } \\
\text { \& SBRT; pres- } \\
\text { ence of epidural } \\
\text { disease }\end{array}$ & NA \\
\hline $\begin{array}{l}\text { Mahadevan } \\
\text { et al., } 2011\end{array}$ & $81 / 60$ & 12 & $\begin{array}{r}93 \% @ \text { last } \\
\text { follow-up }\end{array}$ & NA & $\begin{array}{l}\text { Median } \\
\text { OS: } 11 \\
\text { mos }\end{array}$ & $\begin{array}{c}\text { 25-30 Gy/5 Fx or } 24 \\
\text { Gy/3 Fx (median } \\
\text { dose } 30 \text { Gy/10 Fx) }\end{array}$ & NA & NA \\
\hline $\begin{array}{l}\text { Garg et al., } \\
2011\end{array}$ & $63 / 59$ & 17.6 & 76\%@1yr & NA & $\begin{array}{c}76 \% @ 1 \\
\text { yrs }\end{array}$ & $\begin{array}{l}27 \text { Gy/3 Fx or } 30 \text { Gy/5 } \\
\text { Fx (median dose } 30 \\
\text { Gy/NA Fx) }\end{array}$ & NA & $\begin{array}{l}\text { Prior cEBRT dose } \\
>35 \mathrm{~Gy} \text {, trend } \\
\text { for time interval } \\
\text { to re-treat }>12 \\
\text { mos }(p=0.05) \\
\text { on univariate } \\
\text { analysis }\end{array}$ \\
\hline $\begin{array}{l}\text { Damast et al., } \\
2011\end{array}$ & $97 / 95$ & 12.1 & 66\%@1yr & $46 \%$ & $\begin{array}{r}52-59 \% \\
@ 1 y r\end{array}$ & $\begin{array}{l}20 \text { Gy/5 Fx or } 30 \text { Gy/5 } \\
\text { Fx (median dose } 30 \\
\text { Gy/NA Fx) }\end{array}$ & $\begin{array}{l}30 \mathrm{~Gy} / 5 \mathrm{Fx} \text { associ- } \\
\text { ated w/ better } \\
\text { local control vs } \\
20 \mathrm{~Gy} / 5 \mathrm{Fx}\end{array}$ & $\begin{array}{l}\text { KPS, radiosensi- } \\
\text { tive histology; } \\
\text { time interval } \\
\text { to re-treat }>12 \\
\text { mos }\end{array}$ \\
\hline $\begin{array}{l}\text { Chang et al., } \\
2012\end{array}$ & $54 / 49$ & 17.3 & 81\%@1 yr & $81 \%$ (1 yr) & $\begin{array}{l}\text { Median } \\
\text { OS: } 11 \\
\text { mos }\end{array}$ & $\begin{array}{l}20.6 \text { Gy/1 Fx (mean } \\
\text { cEBRT EQD2 } \\
\text { 39.2Gy) }\end{array}$ & $\begin{array}{l}\text { Presence of epi- } \\
\text { dural disease }\end{array}$ & NA \\
\hline $\begin{array}{l}\text { Thibault et } \\
\text { al., } 2015\end{array}$ & $\begin{array}{l}\text { 56/40 (24/56 } \\
\text { cEBRT } \\
\text { followed by } \\
2 \text { courses } \\
\text { SBRT; } 32 / 56 \\
\text { SBRT \& a 2nd } \\
\text { course SBRT) }\end{array}$ & 6.8 & $\begin{array}{c}81.6 \% @ 1 \\
\text { yr) } / 71.5 \% \\
\text { @ } 2 \text { yrs }\end{array}$ & NA & $\begin{array}{c}48 \% @ \\
1 \text { yr }\end{array}$ & $\begin{array}{l}\text { Median } 30 \text { Gy/4 Fx } \\
(24 / 56, \text { median } \\
\text { cEBRT = 22.5 Gy/5 } \\
\text { Fx \& 1st course } \\
\text { SBRT = 24 Gy/2 Fx; } \\
32 / 56 \text { median 1st } \\
\text { course SBRT = 24 } \\
\text { Gy/2 Fx) }\end{array}$ & $\begin{array}{l}\text { Presence of para- } \\
\text { spinal soft tissue } \\
\text { disease }\end{array}$ & $\begin{array}{l}\text { Time interval } \\
\text { btwn 1st SBRT } \\
\text { \& 2nd SBRT }\end{array}$ \\
\hline
\end{tabular}

GTV = gross tumor volume; NA = not available; OS = overall survival; pts = patients.

are in the process of centrally reviewing all imaging and dosimetry for a pattern of failure analysis. Of note, our cohort consisted predominantly of patients with no epidural disease or low Bilsky grade disease (75.2\% of the cohort), and the proportion of low-grade vs high-grade epidural disease was not identified on univariate analysis as predictive. On further analysis we confirmed that the proportion of cases of high-grade epidural disease (Grade 2 or 3 ) was similar in patients treated with single- or multiplefraction SBRT (32\% vs 44\%, respectively) and, therefore, likely does not explain the result that single-fraction SBRT yielded better local control than multiple-fraction SBRT.

Could single-fraction SBRT be biologically favorable as compared with multiple-fraction SBRT? At present, there are uncontrolled data supporting single-fraction SBRT versus multiple-fraction SBRT and vice versa. ${ }^{1,13,17,30}$ Similarly, radiobiological rationales have been discussed supporting either approach. Those that support singlefraction high-dose SBRT argue that enhanced tumor vas- cular effects and endothelial cell apoptosis yield greater local tumor control, and these pathways are not otherwise activated with more fractionated low dose per fraction regimens. ${ }^{16}$ Additionally, high-dose single-fraction SBRT may induce an additional mechanism of tumor cell death via tumor reperfusion injury. The limited data suggest that a dose per fraction of at least 8-10 Gy, or even up to 15 Gy, is required for these unique effects. In our series, the median dose per fraction was $16.6 \mathrm{~Gy}$ in the single-fraction SBRT cohort and $8 \mathrm{~Gy}$ in the multiple-fraction cohort. Moreover, in the multiple-fraction cohort, $47 \%$ of the patients were treated with $<8$ Gy per fraction regimens. It may be that using low-dose hypofractionated SBRT could have contributed to our higher rates of local failure as has been suggested by other studies. ${ }^{20}$ Of note, when comparing the outcomes using the EDQ2, the linear quadratic formula may overestimate the radiobiological effects with high dose per fraction regimens ( $>15$ Gy), and the ability to use the EQD2 as a tool to generate equivalent doses for 
comparative purposes has been debated in the recent literature. ${ }^{3,13}$ Lastly, some argue that for low $\alpha / \beta$ tumors the biological effectiveness for single-fraction SBRT is likely greater than for multiple-fraction SBRT, and this effect diminishes as the $\alpha / \beta$ increases. At this time, we do not have the ability to determine a priori the tumor $\alpha / \beta$, and it may be a biological confounding factor when trying to describe the effects of dose on tumor control. Those supporting multiple-fraction SBRT argue that re-oxygenation and redistribution yield a radiobiological advantage to enhance local tumor control, the threshold for tumor endothelial cell apoptosis activation is not conclusively known, delivery of repetitive SBRT fractions may overcome tumor hypoxia and induce more dramatic cumulative ischemic injury, and fractionated SBRT may induce a greater immunological response as compared with single-fraction SBRT. ${ }^{11}$ Ultimately, a randomized comparative trial evaluating single-fraction SBRT versus multiple-fraction SBRT will be required; moreover, the trial should evaluate effects specific to both histological type and molecular profile.

The major weakness of this study is its retrospective design. We did observe that $74.3 \%$ of patients had reported improvement in their pain, and, at last follow-up, pain was present in only $46.1 \%$ of patients. These data were based on chart review and not a formalized pain assessment tool with prospective documentation of the numerical pain score. Furthermore, medication details could not be reliably recorded to determine whether the subjectively documented pain response was confounded by the use of analgesics. Ideally, international consensus response end points for pain control are the standard, ${ }^{7}$ but they can only be achieved in a clinical trial. Nevertheless, our results are not unreasonable given prior pain response outcomes as shown in Table 3, and similar to previous studies, our study showed low rates of adverse events. Spine SBRT was well tolerated with respect to acute toxicity in this series. However, these events are typically poorly documented, and a prospective study design and rigorous data acquisition are required for accurate outcomes. Documentation of late effects is more reliable despite the retrospective nature of the study given the permanent nature of the event and urgency of determining a cause upon clinical deterioration. Most importantly, we observed no cases of radiation-induced myelopathy, and this may reflect practice that was consistent with prior published spinal cord dose limits specific to re-irradiation SBRT. ${ }^{26}$ Five percent of our patients did suffer from a VCF. This crude rate is lower than expected, based on our literature review, which shows re-irradiation VCF rates ranging from $10 \%$ to $16 \%$ (Table 3). Notably, Thibault et al. reported no VCF in 19 patients without any prior surgery and treated with multiple-fraction salvage SBRT (most commonly $30 \mathrm{~Gy}$ in 4 fractions). ${ }^{28}$ This is a high-risk group, given that the patients had prior SBRT (many also had prior cEBRT and SBRT) and then were treated with a second course of SBRT to the same level; hence, the cumulative doses to the tumors are much greater than in patients who had previously been treated with cEBRT alone (without SBRT) and were then treated with SBRT. The authors' result may reflect the effect of patient selection. We hypothesize that the low rates of VCF in this population may also be explained by patient selection. For example, $46 \%$ of patients had a surgical procedure prior to SBRT, implying that our cohort consisted mainly of patients at low risk of VCF, as those at high risk of VCF were likely to have undergone a surgical stabilization procedure at some point prior to re-irradiation SBRT. Overall, the low rate of VCF does suggest that this practice is safe with respect to tolerance of the bone, and it highlights the need to understand a priori radiation tolerance of the vertebral body bone for proper patient selection.

This multi-institutional cohort study provides valuable data on efficacy and safety of re-irradiation spine SBRT for patients with spinal metastases after failure of initial cEBRT. We observed high rates of local control and pain control consistent with those reported for smaller singleinstitution series. Patients with a poor performance status (KPS < 70) may not survive long enough to benefit from this resource-intensive therapy. At present, single-fraction SBRT may provide superior rates of efficacy as compared with multiple-fraction SBRT; however, we cannot be definitive, as the quality of the evidence in general is low and dose-finding randomized trials are needed.

\section{References}

1. Al-Omair A, Masucci L, Masson-Cote L, Campbell M, Atenafu EG, Parent A, et al: Surgical resection of epidural disease improves local control following postoperative spine stereotactic body radiotherapy. Neuro Oncol 15:1413-1419, 2013

2. Bilsky MH, Laufer I, Fourney DR, Groff M, Schmidt MH, Varga PP, et al: Reliability analysis of the epidural spinal cord compression scale. J Neurosurg Spine 13:324-328, 2010

3. Brown JM, Brenner DJ, Carlson DJ: Dose escalation, not "new biology", can account for the efficacy of stereotactic body radiation therapy with non-small cell lung cancer. Int J Radiat Oncol Biol Phys 85:1159-1160, 2013

4. Chang UK, Cho WI, Kim MS, Cho CK, Lee DH, Rhee CH: Local tumor control after retreatment of spinal metastasis using stereotactic body radiotherapy; comparison with initial treatment group. Acta Oncol 51:589-595, 2012

5. Chao ST, Koyfman SA, Woody N, Angelov L, Soeder SL, Reddy CA, et al: Recursive partitioning analysis index is predictive for overall survival in patients undergoing spine stereotactic body radiation therapy for spinal metastases. Int J Radiat Oncol Biol Phys 82:1738-1743, 2012

6. Choi CY, Adler JR, Gibbs IC, Chang SD, Jackson PS, Minn AY, et al: Stereotactic radiosurgery for treatment of spinal metastases recurring in close proximity to previously irradiated spinal cord. Int J Radiat Oncol Biol Phys 78:499-506, 2010

7. Chow E, Hoskin P, Mitera G, Zeng L, Lutz S, Roos D, et al: Update of the international consensus on palliative radiotherapy endpoints for future clinical trials in bone metastases. Int J Radiat Oncol Biol Phys 82:1730-1737, 2012

8. Chow E, van der Linden YM, Roos D, Hartsell WF, Hoskin $\mathrm{P}$, Wu JS, et al: Single versus multiple fractions of repeat radiation for painful bone metastases: a randomised, controlled, non-inferiority trial. Lancet Oncol 15:164-171, 2014

9. Cox BW, Spratt DE, Lovelock M, Bilsky MH, Lis E, Ryu S, et al: International Spine Radiosurgery Consortium consensus guidelines for target volume definition in spinal stereotactic radiosurgery. Int J Radiat Oncol Biol Phys 83:e597e605, 2012

10. Damast S, Wright J, Bilsky M, Hsu M, Zhang Z, Lovelock M, et al: Impact of dose on local failure rates after image-guided 
reirradiation of recurrent paraspinal metastases. Int J Radiat Oncol Biol Phys 81:819-826, 2011

11. Dewan MZ, Galloway AE, Kawashima N, Dewyngaert JK, Babb JS, Formenti SC, et al: Fractionated but not single-dose radiotherapy induces an immune-mediated abscopal effect when combined with anti-CTLA-4 antibody. Clin Cancer Res 15:5379-5388, 2009

12. Garg AK, Wang XS, Shiu AS, Allen P, Yang J, McAleer MF, et al: Prospective evaluation of spinal reirradiation by using stereotactic body radiation therapy: The University of Texas MD Anderson Cancer Center experience. Cancer 117:35093516, 2011

13. Guckenberger M, Klement RJ, Allgäuer M, Appold S, Dieckmann K, Ernst I, et al: Applicability of the linear-quadratic formalism for modeling local tumor control probability in high dose per fraction stereotactic body radiotherapy for early stage non-small cell lung cancer. Radiother Oncol 109:13-20, 2013

14. Guckenberger M, Mantel F, Gerszten PC, Flickinger JC, Sahgal A, Létourneau D, et al: Safety and efficacy of stereotactic body radiotherapy as primary treatment for vertebral metastases: a multi-institutional analysis. Radiat Oncol 9:226, 2014

15. Guckenberger M, Sweeney RA, Flickinger JC, Gerszten PC, Kersh R, Sheehan J, et al: Clinical practice of image-guided spine radiosurgery-results from an international research consortium. Radiat Oncol 6:172, 2011

16. Guerrero M, Li XA: Extending the linear-quadratic model for large fraction doses pertinent to stereotactic radiotherapy. Phys Med Biol 49:4825-4835, 2004

17. Heron DE, Rajagopalan MS, Stone B, Burton S, Gerszten PC, Dong X, et al: Single-session and multisession CyberKnife radiosurgery for spine metastases-University of Pittsburgh and Georgetown University experience. J Neurosurg Spine 17:11-18, 2012

18. Howell DD, James JL, Hartsell WF, Suntharalingam M, Machtay M, Suh JH, et al: Single-fraction radiotherapy versus multifraction radiotherapy for palliation of painful vertebral bone metastases-equivalent efficacy, less toxicity, more convenient: a subset analysis of Radiation Therapy Oncology Group trial 97-14. Cancer 119:888-896, 2013

19. Hyde D, Lochray F, Korol R, Davidson M, Wong CS, Ma L, et al: Spine stereotactic body radiotherapy utilizing conebeam CT image-guidance with a robotic couch: intrafraction motion analysis accounting for all six degrees of freedom. Int J Radiat Oncol Biol Phys 82:e555-e562, 2012

20. Laufer I, Iorgulescu JB, Chapman T, Lis E, Shi W, Zhang Z, et al: Local disease control for spinal metastases following "separation surgery" and adjuvant hypofractionated or highdose single-fraction stereotactic radiosurgery: outcome analysis in 186 patients. J Neurosurg Spine 18:207-214, 2013

21. Lutz S, Berk L, Chang E, Chow E, Hahn C, Hoskin P, et al: Palliative radiotherapy for bone metastases: an ASTRO evidence-based guideline. Int J Radiat Oncol Biol Phys 79:965-976, 2011

22. Mahadevan A, Floyd S, Wong E, Jeyapalan S, Groff M, Kasper E: Stereotactic body radiotherapy reirradiation for recurrent epidural spinal metastases. Int J Radiat Oncol Biol Phys 81:1500-1505, 2011

23. Masucci GL, Yu E, Ma L, Chang EL, Letourneau D, Lo S, et al: Stereotactic body radiotherapy is an effective treatment in reirradiating spinal metastases: current status and practical considerations for safe practice. Expert Rev Anticancer Ther 11:1923-1933, 2011
24. Nguyen J, Chow E, Zeng L, Zhang L, Culleton S, Holden $\mathrm{L}$, et al: Palliative response and functional interference outcomes using the Brief Pain Inventory for spinal bony metastases treated with conventional radiotherapy. Clin Oncol (R Coll Radiol) 23:485-491, 2011

25. Sahgal A, Ames C, Chou D, Ma L, Huang K, Xu W, et al: Stereotactic body radiotherapy is effective salvage therapy for patients with prior radiation of spinal metastases. Int J Radiat Oncol Biol Phys 74:723-731, 2009

26. Sahgal A, Ma L, Weinberg V, Gibbs IC, Chao S, Chang UK, et al: Reirradiation human spinal cord tolerance for stereotactic body radiotherapy. Int J Radiat Oncol Biol Phys 82:107-116, 2012

27. Sahgal A, Roberge D, Schellenberg D, Purdie TG, Swaminath A, Pantarotto J, et al: The Canadian Association of Radiation Oncology scope of practice guidelines for lung, liver and spine stereotactic body radiotherapy. Clin Oncol (R Coll Radiol) 24:629-639, 2012

28. Thibault I, Campbell M, Tseng CL, Atenafu EG, Letourneau D, Yu E, et al: Salvage stereotactic body radiotherapy (SBRT) following in-field failure of initial SBRT for spinal metastases. Int J Radiat Oncol Biol Phys 93:353-360, 2015

29. Thibault I, Chang EL, Sheehan J, Ahluwalia MS, Guckenberger M, Sohn MJ, et al: Response assessment after stereotactic body radiotherapy for spinal metastasis: a report from the Spine Response Assessment In Neuro-Oncology (SPINO) group. Lancet Oncol 16:e595-e603, 2015

30. Yamada Y, Bilsky MH, Lovelock DM, Venkatraman ES, Toner S, Johnson J, et al: High-dose, single-fraction imageguided intensity-modulated radiotherapy for metastatic spinal lesions. Int J Radiat Oncol Biol Phys 71:484-490, 2008

\section{Disclosures}

This research was supported by Elekta $\mathrm{AB}$ as a research grant to the principal investigator Dr. Matthias Guckenberger. Each author belongs to the Elekta Spine Study Consortium, which is supported by Elekta AB. Dr. Arjun Sahgal has received honoraria for past educational seminars from Medtronic and Elekta $A B$ and research grants from Elekta AB. The data collection, interpretation, writing and final approval was independent of industry participation. Dr. Grills also reports an ownership interest in Greater Michigan Gamma Knife.

\section{Author Contributions}

Conception and design: all authors. Acquisition of data: all authors. Analysis and interpretation of data: Hashmi, Guckenberger, Sahgal. Drafting the article: all authors. Critically revising the article: all authors. Reviewed submitted version of manuscript: all authors. Approved the final version of the manuscript on behalf of all authors: Sahgal. Statistical analysis: Hashmi, Guckenberger, Sahgal. Administrative/technical/material support: Guckenberger, Sahgal. Study supervision: Guckenberger, Sahgal.

\section{Correspondence}

Arjun Sahgal, Department of Radiation Oncology, University of Toronto, Sunnybrook Health Sciences Centre, 2075 Bayview Ave., Toronto, ON M4N 3M5, Canada. email: arjun.sahgal@ sunnybrook.ca. 